\title{
Road Safety in Kenya: A Case Study of Nairobi Southern Bypass (UCA-2) Road
}

\author{
Mercyberyl Akinyi \\ Sustainable Materials Research \& \\ Technology Centre \\ Jomo Kenyatta University of Agriculture \\ and Technology \\ Nairobi, Kenya \\ mercyberylakinyi@gmail.com
}

\author{
Charles Kabubo \\ Sustainable Materials Research \& \\ Technology Centre \\ Jomo Kenyatta University of Agriculture \\ and Technology \\ Nairobi, Kenya \\ kabcha@jkuat.ac.ke
}

\author{
Mathew M. O. Winja \\ Department of Civil, Construction and \\ Environmental Engineering \\ Jomo Kenyatta University of Agriculture \\ and Technology \\ Nairobi, Kenya \\ winjamathew@gmail.com
}

\begin{abstract}
The fundamental objective of transportation is to ensure that people and goods are safely and effectively moved from one place to another. Analyzing the design consistency is one of the ways in which the road's safety can be maintained or enhanced. In order to obtain a balance in highway design, all the geometric components should, along with being economical functional, be designed to provide safety at speeds likely to occur under ordinary conditions. Distinguishing and treating any geometric inconsistency on an expressway can altogether enhance its safety outcome.
\end{abstract}

\section{Keywords-geometric consistency; accidents; road safety}

\section{INTRODUCTION}

Road accidents are associated not only with injuries and fatalities but with existent or potential financial damage. By the year 2020, the global road traffic fatalities will increase to 1.9 million from the 1.3 million that were recorded in 2014 [1]. According to World Health Organization (WHO), 1.25 million people are killed and 50 million are injured around the world each year in road traffic accidents [2]. In 2011, statistics from WHO approximated Kenya's loss to be at least US\$ 4 billion as a result of road accidents which is about the $11 \%$ of the country's GDP [3]. Forecasts for 2020 raise road accidents to be the third leading cause of death [3]. Every year in Kenya, about 3,000 individuals are killed on road related accidents, which means roughly 68 deaths for every 1,000 enrolled vehicles, which is $30-40$ times more than similar ratios in highly motorized countries [4]. Records from NTSA stated that one in each seven street crashes in Nairobi occurs on the three bypass roads (Eastern, Southern and Northern Bypasses), and a total of 133 individuals died on those bypasses since the opening of the first one in 2014. Between January and November 2014, 37, 31 and 15 individuals were killed on the Eastern Bypass, Northern and Southern bypass roads respectively [5].

It has been established that the Nairobi Southern bypass (UCA-2) is an accident-prone road. The causes of these accidents have not yet been studied systematically, therefore there is a need to carry out a research on road safety on this road. The current study involves the use of linear regression models to investigate the connection between road geometric design consistency and road accidents on the Nairobi Southern bypass (UCA-2) road and to come up with suggestions that will mitigate the problem.

\section{LITERATURE REVIEW}

A road accident is characterized as an irregular occasion which comes after a circumstance in which at least one road user has failed to adapt to the immediate environment [6]. Road safety includes three noteworthy segments: the road system, the human factor, and the vehicle. The way these three segments exist and interact affects the possibility of accidents [4]. According to [7] accidents tend to happen at specific points on the road or among specific types of road users. This infers that there is likely to be a non-random component in the occurrence of most accidents and it should be possible to prevent some incidences from occurring. In this perspective, the Nairobi Southern bypass road has indeed specific areas where accidents tend to happen, consequently the need to analyze the primary causes of car accidents on this bypass road emerges. The first 11 months of 2018 , one of every seven road crash deaths in Nairobi occurred on bypass roads [5]. Since the opening of the first bypass in 2014, about 133 people died on the three bypasses and the trend increases [4]. Accidents may be caused by haziness, road surface wetness, flawed headlamps, darkened visibility, or driver's reflectance [1]. Drivers, pedestrians, and vehicle defects fundamentally affect the possibility of an accident, while travelers and road defects did not essentially cause accidents. Human mistakes, particularly with respect to drivers and pedestrians, is the main accident cause in Kenyan roads, while drivers have been blamed for careless or even drunken driving, pedestrians have been known to spurn traffic rules by crossing the streets at non-assigned points and disrespecting the traffic lights [5]. A road traffic system is intended to be a safe and practical utility. Road traffic related fatalities and injuries are mostly preventable. This is because the danger of an incurring injury in an accident is to a great extent predictable and there are numerous effective countermeasures. The provision of safe, supportable and moderate methods for transport is a key goal in the planning and design of road traffic systems. Wherever such plans and 
strategies are made, they result in a decrease in the number of road accident related deaths and injuries [1].

\section{RESEARCH OBJECTIVES}

The main research objective was to determine the relationship between geometric design consistency and road safety on Nairobi Southern bypass (UCA-2) road in Nairobi County. The specific research objective was to determine the frequency, type and severity of accidents on Nairobi Southern bypass (UCA-2) road in Nairobi County.

\section{RESEARCH METHODOLOGY}

This used a questionnaire survey along with analyzing the consolidated traffic accident data acquired from the Police Stations that recorded accidents that occurred along UCA-2. The study period involved accidents that occurred along Nairobi Southern Bypass between the years 2016 and 2019.

\section{A. Consolidation of Traffic Accident Data}

The traffic accident data of Southern bypass road from Karen, Langata and Industrial area Police Stations collected from the year 2016 to 2018 were consolidated. The raw data were fed in Microsoft Excel and classification of the accidents was done in terms of location, frequency, and severity. A distribution map showing the location, frequency and severity of road accidents from the year 2016 to 2018 was plotted.

\section{B. Data Collection by the Use of Questionnaires}

Data were collected using structured questionnaires which were filled by the main people who frequently used the Nairobi Southern Bypass, namely the Police, drivers, and pedestrians. These data were collected from four locations, namely Kibera, Kikuyu, Ngong and Olesereni. Qualitative data were acquired from the Police and were further analyzed. The sample size was determined using the table published in [9], which provides the necessary sample sizes for given combinations of confidence levels, precision, and variability. The Nairobi Southern Bypass stretches across Nairobi and Kiambu Counties. According to the Kenya Bureau of Statistics, the total population in these counties lies at $6,814,808$ [10]. Using this population as the population size of this study, a confidence level of $95 \%$ and a precision of $10 \%$ the required sample size was found to be 100 . Based on this, 100 questionnaires were distributed to police officers, drivers, and pedestrians. The questionnaires composed of open- and close-ended questions to examine how much the users of Nairobi Southern Bypass knew regarding road safety. The acquired data were the frequency of accident incidences along Nairobi Southern Bypass, the causes of the accidents, and possible solutions, if any. Out of the distributed questionnaires, 48 were returned. Ten of the returned questionnaires were from police officers and the remaining 38 were from drivers and pedestrians.

\section{RESULTS AND DISCUSSION}

\section{A. Occurrence of Traffic Accidents along UCA-2}

From the secondary data, a total of 87 accidents had occurred between June 2016 and April 2019 (Figure 1). The data indicated that $26 \%$ of the accidents occurred in $2016,20 \%$ occurred in $2017,36 \%$ occurred in 2018 while $18 \%$ occurred in
2019. This situation is comparable to accident occurrence in India, where traffic crashes increased by about $5 \%$ per year from 2009 to 2010 [11] .One of the reasons for this increase in traffic accidents was the increased number of vehicles on the road. It is suggested that having a properly coordinated official policy to control how vehicles move along a road can minimize accident occurrence [1].

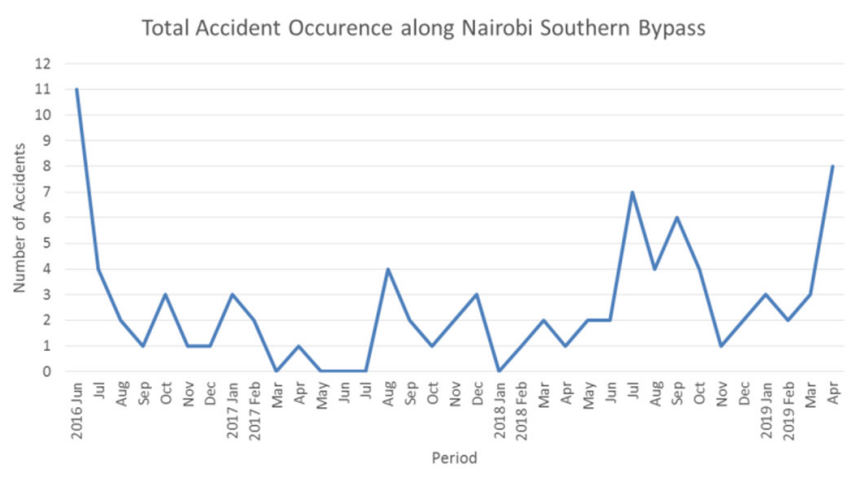

Fig. 1. Accident occurence

\section{B. The Victims}

The main victims of the traffic accidents are passengers, pedestrians, drivers, motor cyclists and pedal cyclists. The secondary data categorized the accident victims according to the severity of the accidents (fatal, seriously injurious or slightly injurious). A fatal accident is defined as an accident resulting in the death of one or more individuals. The definition of a seriously injurious accident covers injuries resulting in a person being detained in hospital and all injuries causing fractures, concussion, crushing, burns (excluding friction burns), severe cuts, internal injuries, severe general shock which require medical treatment even if this does not result in a stay in hospital as an in-patient. A slightly injurious accident is one that leads to a person acquiring a sprain that is not severe (including neck whiplash injury, cuts or bruises). Such victims can also suffer a slight shock requiring first aid [12]. From the acquired secondary data, $39 \%$ of the total recorded accidents were fatal, $47 \%$ were seriously injurious while the remaining $14 \%$ were slightly injurious (Figure 2 ).

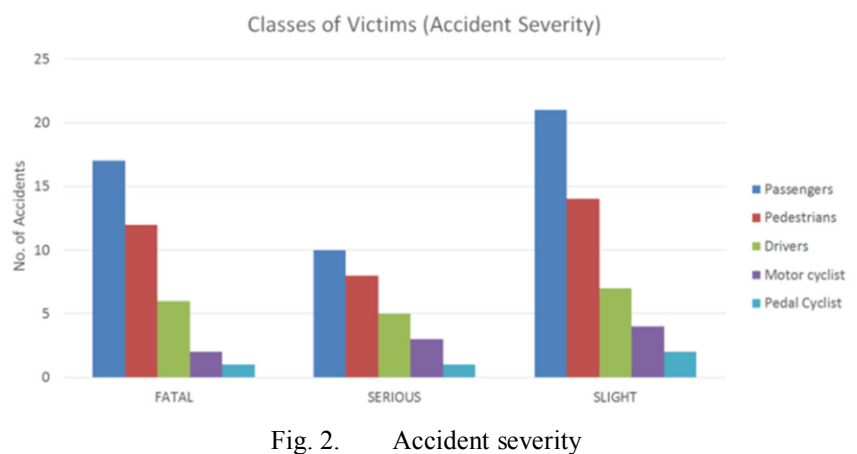

A total of 131 victims were reported by the traffic accidents that occurred along the Nairobi Southern Bypass. It was discovered that passengers were the most affected traffic 
accident victims, composing $35 \%$ of all the victims while pedal cyclists were the least affected victims, covering $4 \%$ of the total number of victims.

\section{Factors Contributing to Traffic Accidents}

According to the field data (Table I), the most common causes of accidents included over speeding, improper overtaking, and driver ignorance of traffic rules. The factors contributing to the traffic accidents occurring along Nairobi Southern Bypass were recorded by the Police in terms of cause codes. Each cause code represented a certain cause of traffic accident. The cause codes include the following:

Code 7- Driver proceeding with high speed

Code 8- Driver failing to keep to the proper lane

Code 10- Driver improperly overtaking

Code 26- Driver losing control of the vehicle

Code 29- Driver misjudging clearance, distance or speed

Code 30- Driver's error of judgment or negligence
Code 68- Pedestrian's error of judgment or negligence

\section{Code 98- Cause not traced}

The traffic accident data indicated that the cause code of $5 \%$ of the accidents that occurred along the Nairobi Southern Bypass could not be traced. Most of the accidents occurred as a result of the driver losing control of the vehicle (Code 26). This factor caused $29 \%$ of the total accidents. Another $11 \%$ of the accidents were caused by speeding while $10 \%$ of the accidents were caused by pedestrians' error of judgment or negligence. Some of the other causes of recorded accidents were driver swerving, skidding, failing to comply with the traffic signs or signals, improperly changing of lanes, sudden stopping, speeding cyclists, etc. It was seen that drivers, pedestrians, and vehicle defects fundamentally cause accidents while travelers and road defects did not essentially do. Human error, particularly of drivers and pedestrians is the main accident cause in Kenyan roads. Drivers have often been blamed for careless driving, while pedestrians have been known to spurn traffic rules by crossing the streets at non-assigned points and disrespecting traffic lights among others [8].

TABLE I. ACCIDENT CAUSES ACCORDING TO THE RESPONDENTS

\begin{tabular}{|c|c|c|c|c|c|c|}
\hline Measures & $\begin{array}{c}5 \\
\text { Strongly agree }\end{array}$ & $\begin{array}{c}4 \\
\text { Agree }\end{array}$ & $\begin{array}{c}3 \\
\text { Undecided }\end{array}$ & $\begin{array}{c}2 \\
\text { Disagree }\end{array}$ & $\begin{array}{c}1 \\
\text { Strongly disagree }\end{array}$ & Average \\
\hline Over speeding & 16 & 13 & & 1 & & 4.5 \\
\hline Improper overtaking & 17 & 10 & 1 & 2 & & 4.4 \\
\hline Driver's failure to obey/ignorance of traffic rules & 8 & 16 & 4 & 0 & 2 & 3.9 \\
\hline Poor roadway maintenance & 1 & 1 & 4 & 13 & 10 & 1.9 \\
\hline Poor road marking & 1 & 4 & 3 & 8 & 14 & 1.9 \\
\hline Defective motor vehicles & 5 & 8 & 4 & 11 & 1 & 3.2 \\
\hline Lack of roadway identification signs & 4 & 4 & 6 & 14 & 2 & 2.7 \\
\hline Lack of speed bumps, raised medians, zebra crossings & 8 & 8 & 4 & 8 & 4 & 3.3 \\
\hline Bad weather & 3 & 5 & 1 & 10 & 10 & 2.4 \\
\hline
\end{tabular}

This case is similar to what was experienced in the United States of America, where $92.6 \%$ of investigated accidents cases were caused by human factors. Environmental factors probably caused $33.8 \%$ of the accident cases while $12.6 \%$ of accident cases may have been caused by vehicular factors $[14,15]$. The research findings further indicated that the main human direct causes of the traffic accidents were speeding and internal distraction. In Saudi Arabia, between the years 1971 and 1997, $3.5 \%$ of the total population was involved in traffic accidents [13]. Excessive speeding and/or drivers' disobedience to traffic signals caused $65 \%$ of the accidents.

According to $[1,16]$ most of the accident occurrences could be avoided or minimized through the following measures:

- Ensuring that traffic safety is one of the main objectives in the planning and implementation of transport networks.

- Better land use practices to reduce traffic volume.

- Setting appropriate speed limits depending on the road function and design.

- Encouraging good road use by improving road layout and design.

- Ensuring that all motor vehicles met the safety standards set for high income countries, including providing safety belts.
- Encouraging the manufacture of vehicles with safer fronts and intelligent systems.

\section{SUMMARY AND CONCLUSIONS}

This paper involved a field study and the analysis of secondary data acquired from the Kenya Police covering the period between 2016 and 2019 regarding road safety on the Nairobi Southern Bypass. The following are the key study results:

- A total of 87 traffic accidents had occurred along Nairobi Southern Bypass during the period between June 2016 and April 2019 with $26 \%$ of the occurring in $2016,20 \%$ in $2017,36 \%$ in 2018 , and $18 \%$ in 2019.

- From the total accident incidences, 39\% of them were fatal, $47 \%$ seriously injurious and 14\% slightly injurious.

- The victims were drivers, passengers, pedestrians, pedal cyclists, and motor cyclists. Out of the 131 victims recorded, passengers led with $35 \%$.

- The major cause of the traffic accidents was over speeding. While bad weather was considered as the least contributor.

Traffic accidents are predictable and can be prevented, or at least minimized. In high income countries, adoption of new 
technology and proper implementation of traffic safety policies to improve traffic safety minimized the number of such incidences.

\section{REFERENCES}

[1] P. Deshpamde, "Road safety and accident prevention in India: A Review", International Journal of Advanced Engineering Technology, Vol. 5, No. 2, pp. 64-68, 2014

[2] M. Touahmia, "Identification of risk factors influencing road traffic accidents”, Engineering, Technology \& Applied Science Research, Vol. 8 , No. 1, pp. 2417-2421, 2018

[3] C. G. Manyara, "Combating road accidents in Kenya. A challemge for an emerging economy", in: Kenya After 50: Reconfiguring Education, Gender and Policy, Springer, 2016

[4] B. Obwocha, "Why bypasses have pushed up road accident toll", Nairobi News, March 20, 2020

[5] W. Odero, M. Khayesa, P. Heda, "Road traffic injuries in Kenya, magnitude causes and status", Injury Control and Safety Promotion, Vol. 10 , No. $1-2$, pp. 53-61, 2003

[6] C. Castro, Human factors of visual and cognitive performance in driving, Taylor \& Francis, 2009

[7] S. Rajalin, H. Summala, "What surviving drivers learn from a fatal accident", Accident Annalysis and Prevention, Vol 29, No. 3, pp. 277283, 1997

[8] L. K. Muchene, "Road accidents in Kenya, A case of poor network or human error", $59^{\text {th }}$ ISI World Statistics Congress, Hong Kong, China, August 25-30, 2013

[9] I. D. Glenn, "Determining sample size", University of Florida, available at: https://www.tarleton.edu/academicassessment/documents/Samplesize .pdf, 1992

[10] Kenya National Bureau of Statistics, 2019 Kenya population and housing census, Volume 1, Population by county and sub-county, KNBS, 2019

[11] Ministry of Affairs, Accidental deaths and suicides, Government of India, 2008

[12] L. Harms-Ringdahl, Guide to safety analysis for accident prevention, IRS Riskhantering AB, 2013

[13] S. Ansari, F. Akhdar, M. Mandoorah, K. Moutaery, "Causes and effects of road traffic accidents in Saudi Arabia”, Public Health, Vol. 114, No. 1 , pp. 37-39, 2000

[14] C. W. Ndung'u, R. M. Bonface, L. K. Mwai, "Analysis of causes \& response strategies of road traffic accidents in Kenya", Journal of Business and Management, Vol. 17, No. 4, pp. 58-77, 2015

[15] National Highway Traffic Safety Administration, Tri-level study of the causes of traffic accidents, U.S. Department of Transportation, National Highway Traffic Safety Administration, 1979

[16] M. Z. Hasanpour, M. R. Ahadi, A. S. Moghadam, G. A. Behzadi, "Variable speed limits: Strategies to improve safety and traffic parameters for a bottleneck", Engineering, Technology \& Applied Science Research, Vol. 7, No. 2, pp. 1535-1539, 2017 